Article

\title{
Quantifying Chlorophyll Fluorescence Parameters from Hyperspectral Reflectance at the Leaf Scale under Various Nitrogen Treatment Regimes in Winter Wheat
}

\author{
Min Jia ${ }^{1,2,3,4}$, Dong Li ${ }^{1,2,3,4}$, Roberto Colombo ${ }^{5}$, Ying Wang 1,2,3,4, Xue Wang 1,2,3,4, \\ Tao Cheng ${ }^{1,2,3,4} \mathbb{D}$, Yan Zhu ${ }^{1,2,3,4} \mathbb{D}$, Xia Yao ${ }^{1,2,3,4, *}$, Changjun Xu ${ }^{6}$, Geli Ouer ${ }^{6}$, Hongying Li ${ }^{6}$ \\ and Chaokun Zhang 6 \\ 1 National Engineering and Technology Center for Information Agriculture, Nanjing Agricultural University, \\ Nanjing 210095, China; 2016201075@njau.edu.cn (M.J.); 2016201077@njau.edu.cn (D.L.); \\ 2018101175@njau.edu.cn (Y.W.); wangxue@njau.edu.cn (X.W.); tcheng@njau.edu.cn (T.C.); \\ yanzhu@njau.edu.cn (Y.Z.) \\ 2 Key Laboratory for Crop System Analysis and Decision Making, Ministry of Agriculture, Nanjing 210095, \\ China \\ 3 Jiangsu Key Laboratory for Information Agriculture, Nanjing 210095, China \\ 4 Jiangsu Collaborative Innovation Center for Modern Crop Production, Nanjing 210095, China \\ 5 Remote Sensing of Environmental Dynamics Laboratory, Department of Earth and Environmental \\ Science (DISAT), Università di Milano-Bicocca, Piazza della Scienza 1, 20126 Milan, Italy; \\ roberto.colombo@unimib.it \\ 6 Qinghai Basic Geographic Information Center, Qinghai 810000, China; qhxcj@qhgis.cn (C.X.); \\ oegl@qhgis.cn (G.O.); floralee@qhgis.cn (H.L.); zhang_ck@qhgis.cn (C.Z.) \\ * Correspondence: yaoxia@njau.edu.cn; Tel.: +86-25-84396565; Fax: +86-25-84396672
}

Received: 8 October 2019; Accepted: 23 November 2019; Published: 29 November 2019

Abstract: Chlorophyll fluorescence (ChlF) parameters, especially the quantum efficiency of photosystem II (PSII) in dark- and light-adapted conditions (Fv/Fm and $\mathrm{Fv}^{\prime} / \mathrm{Fm}^{\prime}$ ), have been used extensively to indicate photosynthetic activity, physiological function, as well as healthy and early stress conditions. Previous studies have demonstrated the potential of applying hyperspectral data for the detection of ChlF parameters in vegetation. However, the performance of spectral features that have been documented to estimate ChlF is not ideal and is poorly understood. In this study, ChlF parameters and leaf reflectance were collected in two field experiments involving various wheat cultivars, nitrogen (N) applications, and plant densities, during the growing seasons of 2014 to 2015 and 2015 to 2016. Three types of spectral features, including vegetation indices (VIs), red edge position (REP), and wavelet features, were used to quantify ChlF parameters $\mathrm{Fv} / \mathrm{Fm}$ and $\mathrm{Fv}^{\prime} / \mathrm{Fm}^{\prime}$. The results indicated that traditional chlorophyll fluorescence vegetation indices (ChlF VIs), such as the curvature index (CUR) and D705/D722 were capable of detecting $\mathrm{Fv} / \mathrm{Fm}$ and $\mathrm{Fv}^{\prime} / \mathrm{Fm}^{\prime}$ under various scenarios. However, the wavelet-based REP (WREP-S4) and the wavelet feature (WF) (704 nm, scale 4) yielded higher accuracy than other spectral features in calibration and validation datasets. Moreover, the bands used to calculate WREP-S4 and WF (704 nm, scale 4) were all centered in the red edge region ( 680 to $760 \mathrm{~nm}$ ), which highlighted the role of the red edge region in tracking the change of active ChlF signal. Our results are supported by previous studies, which have shown that the red edge region is vital for estimating the chlorophyll content, and also the ChlF parameters. These findings could help to improve our understanding of the relationships among active ChlF signal and reflectance spectra.

Keywords: chlorophyll fluorescence (ChlF) parameter; vegetation indices (VIs); red edge position (REP); continuous wavelet analysis (CWA); maximal photochemical efficiency of PSII (Fv/Fm), photochemical efficiency of PSII in the light $\left(\mathrm{Fv}^{\prime} / \mathrm{Fm}^{\prime}\right)$ 


\section{Introduction}

Chlorophyll fluorescence (ChlF) is a reaction of the photosynthesis apparatus to cope with excess light energy, which is accompanied with photochemical reactions and heat dissipation [1]. When the maximum photosynthetic rate is impaired, ChlF increases under many non-optimal environments. Therefore, ChlF is a direct indicator of electron transport and photosynthetic activity [2]. The ChlF parameters have been measured using a pulse-amplitude modulation fluorometer with different active light sources under light-adapted or dark-adapted conditions. ChlF parameters which are widely used to express the energy transfer of plant photosynthesis are relevant ChlF variables that have been calculated based on standard methodologies as reported in the PAM-2000 manual [3].

In contrast to traditional remote sensing techniques, ChlF produced solely by plants, rapidly captures the specific and instantaneous change of plants' physiology status and response to various nutritional treatments, heat, and water conditions [4,5]. Among all the ChlF parameters, Fv/Fm, which is the ratio of variable to maximal fluorescence, is the initial maximal efficiency of photons captured by open photosystem II (PSII) reaction centers [6], and is a widely used parameter representing the health and growth of plants [7-9]. The $\mathrm{Fv}^{\prime} / \mathrm{Fm}^{\prime}$ parameter, which is the efficiency of energy harvesting by oxidized (open) PSII reaction centers in light, serves as an indicator to assess plant stress, nutrient, and health status [10]. Both $\mathrm{Fv} / \mathrm{Fm}$ and $\mathrm{Fv}^{\prime} / \mathrm{Fm}^{\prime}$ are closely related to the actual activity of plant photosynthetic tissue, and have been applied to monitor the physiological status of plants and their reactions to the environment [11].

Given the small ChlF signal and low efficiency for monitoring, there has been limited progress in retrieving ChlF parameters at the leaf and canopy scales. Most studies have mainly focused on the vegetation indices (VIs) [12-16]. The essence of estimating ChlF parameters using VIs is based on the fact that ChlF emission is superimposed on the leaf reflectance in the red edge region (680 to $800 \mathrm{~nm}$ ). The VIs used to monitor ChlF parameters is a reflectivity index reflecting fluorescence intensity, rather than a definite physical quantity. These ChlF VIs have been divided into two categories, the reflectance ratio VIs and the derivative VIs. For reflectance ratio VIs, the curvature index (CUR), R685/R655, and R680/R630 have shown good relationships with ChlF parameters [12,13]. Meanwhile, derivative VIs, such as (D688*D710)/D697² (DPi), D705/D722, and D730/D706, have been developed to detect the subtle ChlF signal, because it has been found that the double-peak feature at 690 to $710 \mathrm{~nm}$ in the derivative reflectance was related to the natural fluorescence in both short-term and long-term stress experiments $[14,17]$. Although the photochemical reflectance index (PRI) has been used as an interspecific index of photosynthetic radiation use efficiency for foliar and canopy leaves [18], there has been some predicted bias when estimating Fv/Fm using PRI [13].

The ChlF signal centers in the red edge region (680 to $800 \mathrm{~nm}$ ) and the VIs used to estimate the ChlF parameters are mainly composed of bands in the red edge region, which can makes it possible to monitor ChlF parameters using the red edge position (REP). The REP, defined as the wavelength of inflection point in the red edge region, has been widely used as an indicator of chlorophyll (Chl) content of various plants [19]. Many techniques have been developed to extract REP including linear interpolation (LI) [20], linear extrapolation (LE) [21], polynomial fitting (PF) [22], inverted Gaussian (IG) [23], and wavelet-based REP extraction technique (WREP) [19]. In the past few decades, although REP has been successfully applied to monitor Chl content, it has never been used to monitor plant physiological parameters, especially ChlF parameters directly related to photosynthesis and plant function. Moreover, the most suitable algorithm of REP extraction for ChlF parameters estimation is still unclear.

In general, wavelength selection of ChlF VIs is mainly based on existing research or experience, and therefore the bands relevant to ChlF characteristics have not been fully explored and utilized. However, continuous wavelet analysis (CWA) can capture the rich and subtle changes of the reflectance by simulating the similarity between the wavelet function at different scales within a continuous region [24]. This approach improves the use of spectral libraries and gives a better performance for estimating plant traits relative to that of VIs, including Chl content, leaf water content, and leaf mass 
per area (LMA) $[25,26]$. However, to date, little is known regarding the selection of optimal spectral features using CWA to estimate plant ChlF parameters.

In this context, the objectives of this study included the following: (1) to identify the ChlF parameters in light- and dark-adapted conditions which are more related to plant physiological and biochemical status; (2) to investigate the potential of CWA and REP to exploit hyperspectral reflectance for ChlF parameter estimation under different treatments involving variable sowing densities, development stages, and $\mathrm{N}$ fertilization; and (3) to determine the sensitive features relevant to the representative ChlF parameters. It is projected that this research could provide an experimental basis and technical support for estimating ChlF parameters via hyperspectral reflectance.

\section{Materials and Methods}

\subsection{Experimental Design}

Two experiments of winter wheat were conducted at Rugao $\left(32^{\circ} 15^{\prime} \mathrm{N}, 120^{\circ} 38^{\prime} \mathrm{E}\right)$ in Jiangsu Province, China, during the growing seasons of 2014 to 2015 and 2015 to 2016. The data collected during the 2014 to 2015 growing season was only dedicated to the calibration of spectral computations, whereas that of the 2015 to 2016 dataset was used mainly as validation. As shown in Table 1, the experimental variables included various nitrogen $(\mathrm{N})$ applications, planting densities, cultivars, and growing stages. A completely randomized block design was used with three replications in each experiment. Prior to seeding, $120 \mathrm{~kg} \mathrm{ha}^{-1} \mathrm{P}_{2} \mathrm{O}_{5}$ and $135 \mathrm{~kg} \mathrm{ha}^{-1} \mathrm{KCl}$ were applied for all treatments. For two winter wheat cultivars, the plant type of Shengxuan 6 is dispersed, and that of Yangmai 18 is erect. Then, $50 \%$ nitrogen $(\mathrm{N})$ fertilizer was applied at the pre-planting stage and jointing period. Additional details about the experiments are provided in Table 1 . The plot size was $6.5 \times 5 \mathrm{~m}^{2}$ for two experiments. The management of disease, pests, and weeds followed standard practices for chemical control in the local region.

Table 1. Basic information of two field experiments at Rugao.

\begin{tabular}{|c|c|c|c|c|c|c|}
\hline $\begin{array}{l}\text { Experiment } \\
\text { (Exp.) }\end{array}$ & Season & $\begin{array}{l}\text { Rowledge } \\
\text { (cm) }\end{array}$ & Cultivar & $\begin{array}{l}\text { N rate } \\
\text { (kg/ha) }\end{array}$ & 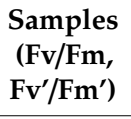 & $\begin{array}{c}\text { Sampling Date } \\
\text { (Date/Phenological } \\
\text { Stages/DAS)/Function }\end{array}$ \\
\hline Exp. 1 & 2014 to 2015 & 25,40 & $\begin{array}{l}\text { Shengxuan } 6 \\
\text { (V1) } \\
\text { Yangmai } 18 \\
\text { (V2) }\end{array}$ & $\begin{array}{c}0(\mathrm{~N} 0) \\
150(\mathrm{~N} 2) \\
300(\mathrm{~N} 4)\end{array}$ & $\begin{array}{l}36,35 \\
36,36 \\
36,36 \\
33,33 \\
12,12\end{array}$ & $\begin{array}{c}\text { (9 }{ }^{\text {th }} \text { Apr/booting/164), } \\
\left(16^{\text {th }} \text { Apr/heading/172), }\right. \\
\left(26^{\text {th }} \text { Apr/anthesis/179), }\right. \\
\left(1^{\text {st }} \text { May/filling/187), }\right. \\
\text { (7 } 7^{\text {th }} \text { May/7days after } \\
\text { filling/193) } \\
\text { (calibration) }\end{array}$ \\
\hline Exp. 2 & 2015 to 2016 & $20,30,40$ & $\begin{array}{l}\text { Yangmai } 18 \\
\text { (V2) }\end{array}$ & $\begin{array}{c}0(\mathrm{~N} 0) \\
80(\mathrm{~N} 1) \\
150(\mathrm{~N} 2) \\
220(\mathrm{~N} 3)\end{array}$ & $\begin{array}{l}62,35 \\
62,30 \\
62,30\end{array}$ & 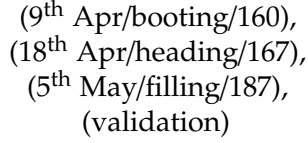 \\
\hline
\end{tabular}

DAS: days after sowing.

\subsection{Data Acquisition}

\subsubsection{Measurement of ChlF Parameters}

The ChlF parameters (Table 2) of wheat leaves were measured using a portable modulated chlorophyll fluorometer PAM-2500 (Heinz Walz GmbH, Effeltrich, Germany) at several significant growth stages in two growing seasons. For each treatment, the top three fully expanded leaves of wheat were clamped at the center of PAM-2500 leaf clip holder. All light-adapted ChlF parameters were measured between 10:00 and 12:00 $\mathrm{h}$ in sunny conditions, whereas dark-adapted ChlF parameters (Fo, Fm, Fv/Fm), were obtained around 16:00 $\mathrm{h}$ after the leaves were subjected to dark adaptation for 30 minutes. 
Table 2. Chlorophyll fluorescence (ChlF) parameters used in this study.

\begin{tabular}{|c|c|c|c|}
\hline & Abbreviation & Description & Equation \\
\hline \multirow{3}{*}{$\begin{array}{l}\text { dark-adapted } \\
\text { condition }\end{array}$} & Fo & Minimal fluorescence yield & \\
\hline & Fm & Maximal fluorescence yield & \\
\hline & $\mathrm{Fv} / \mathrm{Fm}$ & $\begin{array}{l}\text { Maximal photochemical } \\
\text { efficiency of PSII }\end{array}$ & $=(\mathrm{Fm}-\mathrm{Fo}) / \mathrm{Fm}$ \\
\hline \multirow{7}{*}{ light-adapted condition } & Fs & Steady-state fluorescence & \\
\hline & $\mathrm{Fo}^{\prime}$ & $\begin{array}{l}\text { Initial fluorescence in the } \\
\text { presence of NPQ }\end{array}$ & \\
\hline & $\mathrm{Fm}^{\prime}$ & $\begin{array}{l}\text { Maximal fluorescence in the } \\
\text { presence of NPQ }\end{array}$ & \\
\hline & $\mathrm{Fv}^{\prime} / \mathrm{Fm}^{\prime}$ & $\begin{array}{l}\text { Photochemical efficiency of } \\
\text { PSII in the light }\end{array}$ & $=\left(\mathrm{Fm}^{\prime}-\mathrm{Fs}^{\prime}\right) / \mathrm{Fm}^{\prime}$ \\
\hline & $\mathrm{Y}(\mathrm{II})$ & Yield of quantum efficiency & \\
\hline & NPQ & $\begin{array}{l}\text { Non-photochemical } \\
\text { quenching calculated with Fm }\end{array}$ & $=\left(\mathrm{Fm}-\mathrm{Fm}^{\prime}\right) / \mathrm{Fm}^{\prime}$ \\
\hline & ETR & $\begin{array}{l}\text { Apparent photosynthetic } \\
\text { electron transport rate }\end{array}$ & $=$ Yield $\times$ PFD $\times 0.5 \times 0.8$ \\
\hline
\end{tabular}

\subsubsection{Measurement of Leaf Physiological Parameters}

After the ChlF parameters were obtained, measurements of leaf gas exchange, including net photosynthetic rate (An) and stomatal conductance (gs), were taken on the same leaves under field conditions. These data were collected between 10:00 and 13:00 h on clear days using a LI-6400 portable photosynthesis system (LiCOR Inc., Lincoln, Nebraska, USA) during the 2014 to 2015 growing season. During the measurements, the photosynthetically active radiation (PAR) was set to $1200 \mu \mathrm{mol} \cdot \mathrm{m}^{-2} \cdot \mathrm{s}^{-1}$, which corresponds to saturation in the field. The temperature and concentration of $\mathrm{CO}_{2}$ in the chamber were maintained at $25^{\circ} \mathrm{C}$ and $380 \mu \mathrm{mol} \cdot \mathrm{mol}^{-1}$, respectively. The airflow rate through the leaf chamber was held constant at $500 \mu \mathrm{mol} \cdot \mathrm{s}^{-1}$. Air pressure and relative humidity were adjusted to near ambient levels. Finally, the plant leaves to be measured were transported to the laboratory for measuring the reflectance spectra.

\subsubsection{Measurement of Leaf Reflectance}

Leaf reflectance spectra were measured using an ASD FieldSpec Pro FR2500 spectrometer coupled with a leaf clip accessory (Analytical Spectral Devices, Boulder, CO, USA). The spectrometer, operating in the 350 to $2500 \mathrm{~nm}$ spectral range, provided a sampling interval of $1.4 \mathrm{~nm}$ and a spectral resolution of $3 \mathrm{~nm}$ between 350 and $1050 \mathrm{~nm}$, and $2 \mathrm{~nm}$ and $10 \mathrm{~nm}$ between 1050 and $2500 \mathrm{~nm}$, respectively. The leaf clip, used to collect leaf reflectance, was combined with a high-intensity reflectance probe attachment. It was equipped with an internal artificial light source that was independent of solar illumination. The clip also provided white and black background panels, of which the reflectance was approximately $100 \%$ and $0 \%$, respectively. The field of view was limited to a diameter of $1.3 \mathrm{~cm}$ for the leaf clip, therefore measurements of leaf reflectance were not conducted before the jointing stage of winter wheat. After the dark current correction and optimization, the reflectance of the white panel was recorded as the reference. Individual spectral measurements, based on an average of three scans, were determined by standardizing a sample spectrum to that of the white reference panel.

\subsubsection{Optical Measurements of Pigments in Laboratory}

After the reflectance measurements, the surface area and fresh weight were determined immediately. The leaf area was measured with LI 3000 (LI-COR, Inc., Lincoln, NE, USA). Then, the leaves were cut into pieces and put into a volumetric flask $(25 \mathrm{ml})$. The pigment content was extracted by ethanol (95\%) and determined using a V1200 spectrophotometer (MAPADA Co., Shanghai, China) following standard wet chemistry procedures [27]. Then, the concentration $(\mu \mathrm{g} / \mathrm{ml})$ of $\mathrm{Chl} \mathrm{a}$, 
$\mathrm{Chl} \mathrm{b}$, and carotenoid (Car) of samples were determined. Finally, the area based $\mathrm{Chl}_{\mathrm{ab}}(\mathrm{Chl} \mathrm{a}+\mathrm{Chl} \mathrm{b}$, $\left.\mathrm{ug} / \mathrm{cm}^{2}\right)$ and Car $\left(\mathrm{ug} / \mathrm{cm}^{2}\right)$ were calculated.

\subsection{Data Analysis and Utilization}

\subsubsection{Calculation of VIs}

Five groups of VIs (Table 3) were calculated using the reflectance data. The first group was the ChlF VIs, including reflectance ratio VIs and derivative Vis, which were classified according to the previous study [28]. The second group was about status VIs, involving PRI and REPs extracted by five algorithms. These indices were selected because the variation of ChlF parameters is influenced comprehensively by biological activity and environmental conditions (fertilizer, solar radiation, temperature, and water) $[29,30]$. Thus, several VIs related to Chl content, structure properties, and water content were involved in this study for the detection of ChlF parameters.

\subsubsection{Methods for REP Extractions}

The explanation of five algorithms for REP extractions (listed in Table 3) are as follows:

(1) Linear Interpolation (LI)

REP is determined using a simple four-point LI method near the midpoint of the region 670 to 780 $\mathrm{nm}$, where the reflectance can be simplified to a straight line [21]. The calculation procedure is shown as below:

$$
\begin{gathered}
\mathrm{R}_{\mathrm{re}}=\left(\mathrm{R}_{670}+\mathrm{R}_{780}\right) / 2 \\
\mathrm{REP}=700+40 \times \frac{\mathrm{R}_{\mathrm{re}}-\mathrm{R}_{700}}{\mathrm{R}_{740}-\mathrm{R}_{700}}
\end{gathered}
$$

where $R_{r e}$ is the reflectance average of $670 \mathrm{~nm}$ and $780 \mathrm{~nm}$.

(2) Polynomial Fitting (PF)

A fifth-order PF function (shown below) was used to fit the reflectance curve over the red edge region 670 to $780 \mathrm{~nm}$. The REP is defined as the wavelength corresponding to the maximum value of the first derivative spectra curve which is obtained by taking the first derivative of the fitted curve [23].

$$
\mathrm{R}(\lambda)=a_{0}+\sum_{i=1}^{5} a_{i} \lambda^{i}
$$

where $\lambda$ represents 111 bands of the reflectance from $670 \mathrm{~nm}$ to $780 \mathrm{~nm}$.

(3) Linear Extrapolation (LE)

The first derivative spectra were obtained by a first difference transformation and then smoothing with the Savitzky-Golay method. Two points in the far-red region (680 to $700 \mathrm{~nm}$ ) and two points in the near-infrared region (NIR) $(725$ to $760 \mathrm{~nm}$ ) of the first derivative spectra were identified to construct two straight lines as follows [22].

$$
\begin{aligned}
& \mathrm{FDR}=\mathrm{m}_{1} \lambda+\mathrm{c}_{1} \\
& \mathrm{FDR}=\mathrm{m}_{2} \lambda+\mathrm{c}_{2}
\end{aligned}
$$

where FDR is the first derivative spectra and $\mathrm{m} 1, \mathrm{~m} 2, \mathrm{c} 1$, and $\mathrm{c} 2$ represent the slopes and intercepts of the two respective straight lines. The REP is determined as the wavelength corresponding to the intersection of the straight lines as below:

$$
\mathrm{REP}=\frac{-(\mathrm{c} 1-\mathrm{c} 2)}{\mathrm{m} 1-\mathrm{m} 2}
$$


(4) Wavelet-Based Red Edge Position (WREP)

The WREP is extracted in the red edge region of wavelet spectra as follows [20]:

$$
\mathrm{WREP}=\frac{w_{1} \lambda_{2}-w_{2} \lambda_{1}}{w_{1}-w_{2}}
$$

where $\mathrm{w}_{1}$ and $\mathrm{w}_{2}$ are the wavelet coefficients of the two adjacent points below and above the horizontal zero line in the red edge region, respectively. $\lambda_{1}$ and $\lambda_{2}$ are the wavelengths corresponding to $w_{1}$ and $w_{2}$, separately. The WREP has shown strong correlations with Chl content at the leaf level, especially at low scales [20]. Therefore, in this study, WREP was extracted at two low scales, such as scale 3 (WREP-S3) and scale 4 (WREP-S4).

\subsubsection{Continuous Wavelet Analysis (CWA)}

CWA is a powerful mathematical tool that processes spectroscopic signals and provides an effective approach for acquiring information about plant traits [31,32]. CWA is typically conducted in two steps, namely, continuous wavelet transform (CWT) and feature selection. In this study, CWT was analyzed using the "WV_CWT" function in IDL 8.3 (ITT Visual Information Solutions, Boulder, CO, USA).

A signal matrix $(1 \times n)$ was generated by a wavelet function based on a given wavelet scale, a translational wavelet function, and a spectral signal. Thus, a $\mathrm{n} \times \mathrm{m}$ dimensional continuous wavelet transform coefficient matrix was produced after wavelet transformation at the $\mathrm{m}$ scale (where $\mathrm{n}$ represents the band and $\mathrm{m}$ is the scale). In this study, the mother wavelet function is the second derivative of the Gaussian function, because it has a similar shape to the leaf absorption features [33]. Each reflectance in the range 400-1000 nm where ChlF occurs was decomposed into continuous components at various scales. The CWT operations were conducted at a power of $2\left(2^{1}, 2^{2}, \ldots, 2^{8}\right)$ and are called by their respective power numbers (i.e., scale 1 , scale $2, \ldots$ scale 8 ). Random noise due to reflectance measurement can be contained in the low scale components [32], and hence only the wavelet features at scales 3 to 8 were analyzed to produce a correlation scalogram (coefficient of determination, $\mathrm{R}^{2}$ ). The regions with the highest $1 \%$ of $\mathrm{R}^{2}$ for wavelet feature and ChlF parameters $\left(\mathrm{Fv} / \mathrm{Fm}\right.$ and $\left.\mathrm{Fv}^{\prime} / \mathrm{Fm}^{\prime}\right)$ were highlighted in red, and the wavelet features with the highest $\mathrm{R}^{2}$ in each region were extracted. 
Table 3. Algorithms for different spectral features reported in literature.

\begin{tabular}{|c|c|c|c|}
\hline & Spectral Feature Type & Index Name (Abbreviation) & Index Formulation And Reference \\
\hline \multirow{21}{*}{ VI } & \multirow{5}{*}{ Reflectance ratio VI } & Curvature index (CUR) & $(\mathrm{R} 675 \times \mathrm{R} 691) / \mathrm{R} 63^{2}[12]$ \\
\hline & & $\operatorname{RVI}(750,800)$ & $\mathrm{R} 750 / \mathrm{R} 800[12]$ \\
\hline & & RVI $(685,655)$ & R685/R655 [12] \\
\hline & & RVI $(680,630)$ & R680/R630 [13] \\
\hline & & Double-peak index (DPi) & $(\mathrm{D} 688 \times \mathrm{D} 710) / \mathrm{D} 697^{2}[14]$ \\
\hline & \multirow{4}{*}{ Derivative VI } & D705/D722 & D705/D722 [14] \\
\hline & & D730/D706 & $\mathrm{D} 730 / \mathrm{D}_{7} 06[14]$ \\
\hline & & DP22 & $\mathrm{D} \lambda \rho / \mathrm{D} 720[14]$ \\
\hline & & DPRI & $\mathrm{D} \lambda \rho / \mathrm{D}(\lambda \rho+12 \mathrm{~nm})[14]$ \\
\hline & physiological VI & Photochemical reflectance index (PRI) & $(\mathrm{R} 531-\mathrm{R} 570) /(\mathrm{R} 531+\mathrm{R} 570)[33]$ \\
\hline & \multirow{2}{*}{ Chl VI } & MERIS terrestrial chlorophyll index (MTCI) & $(\mathrm{R} 754-\mathrm{R} 709) /(\mathrm{R} 709-\mathrm{R} 681)[34]$ \\
\hline & & Red edge chlorophyll index (CIred edge) & $(\mathrm{R} 800 / \mathrm{R} 720)-1[35,36]$ \\
\hline & \multirow{2}{*}{ Structure VI } & Normalized difference vegetation index (NDVI) & $(\mathrm{R} 810-\mathrm{R} 690) /(\mathrm{R} 810+\mathrm{R} 690)[37]$ \\
\hline & & Enhanced vegetation index (EVI) & $2.5 \times(\mathrm{R} 810-\mathrm{R} 690) /(\mathrm{R} 810+2.4 \times \mathrm{R} 690+1)[38]$ \\
\hline & \multirow{2}{*}{ Water VI } & Normalized difference water index (NDWI) & $(\mathrm{R} 850-\mathrm{R} 1240) /(\mathrm{R} 850+\mathrm{R} 1240)[39]$ \\
\hline & & Water index (WI) & R850/R970 [40] \\
\hline & \multirow{5}{*}{ REP } & Linear interpolation $\left(\mathrm{REP}_{\mathrm{LI}}\right)$ & Explained as below, [41] \\
\hline & & Polynomial fitting $\left(\mathrm{REP}_{\mathrm{PF}}\right)$ & Explained as below, [42] \\
\hline & & Linear extrapolation $\left(\mathrm{REP}_{\mathrm{LE}}\right)$ & Explained as below, [21] \\
\hline & & Wavelet-based REP extraction (WREP-S3) & Explained as below, [19] \\
\hline & & Wavelet-based REP extraction (WREP-S4) & Explained as below, [17] \\
\hline
\end{tabular}




\subsection{Statistical Analysis}

The VIs, REPs, and CWA were applied to build models to monitor the ChlF parameters of wheat leaf. The relationships among the spectral features and ChlF parameters were established from the data collected during the 2014 to 2015 growing season, which were validated using the data acquired during the 2015 to 2016 growing season. The 1:1 plot of the measured and predicted data was used to evaluate the model fitness. Calibration $R^{2}\left(R^{2}\right.$ ), see Equation (8), and the root mean square error of calibration $\left(\mathrm{RMSE}_{\mathrm{C}}\right)$, see Equation (9), were statistical parameters used to evaluate the performances of all models in calibration. For validation, they are validation $R^{2}\left(R^{2} v\right)$, see Equation (10); bias (Bias), see Equation (11); the root mean square error of prediction (RMSEv), see Equation (12); and the relative root mean square error of prediction (RRMSEv), see Equation (13). Higher values of $R^{2} C, R^{2} v$, and lower values of RMSE ${ }_{C}$, Bias, RMSEv, and RRMSEv indicate higher accuracy of the model.

$$
\begin{gathered}
R_{C}^{2}=\left(\frac{\sum_{i=1}^{n}\left(X_{i}-\bar{X}\right)\left(Y_{i}-\bar{Y}\right)}{\sqrt{\sum_{i=1}^{n}\left(X_{i}-\bar{X}\right)^{2}} \sqrt{\sum_{i=1}^{n}\left(Y_{i}-\bar{Y}\right)^{2}}}\right)^{2} \\
\operatorname{RMSE}_{C}=\sqrt{\sum_{i=1}^{n}\left(Y_{i}-M_{i}\right)^{2} \frac{1}{n}} \\
R_{V}^{2}=\left(\frac{\sum_{i=1}^{n}\left(Y_{i}^{\prime}-\overline{Y_{i}^{\prime}}\right)\left(Y_{i}-\bar{Y}\right)}{\sqrt{\sum_{i=1}^{n}\left(Y_{i}^{\prime}-\overline{Y_{i}^{\prime}}\right)^{2}} \sqrt{\sum_{i=1}^{n}\left(Y_{i}-\bar{Y}\right)^{2}}}\right)^{2} \\
\operatorname{Bias}=\frac{\sum_{i}\left(Y_{i}-Y_{i}^{\prime}\right)}{n} \\
\operatorname{RMSE}_{v}=\sqrt{\sum_{i=1}^{n}\left(Y_{i}-Y_{i}^{\prime}\right)^{2}} \frac{1}{n} \\
\operatorname{RRMSE}_{v}=\frac{\sqrt{\sum_{i=1}^{n}\left(M_{i}-Y_{i}\right)^{2} \frac{1}{n}}}{\overline{Y_{i}}} \times 100 \%
\end{gathered}
$$

where $Y_{i}$ is the measured value of samples, $M_{i}$ is the predicted value of samples in the calibration dataset, $\bar{X}$ is the average of $X_{i}, \bar{Y}$ is the average of $Y_{i}, Y_{i}^{\prime}$ is the predicted values, $\bar{Y}^{\prime}$ is the average of $Y_{i}^{\prime}$ for the validation dataset, and $\mathrm{n}$ is the number of samples.

\section{Results}

\subsection{Relationships among Leaf Pigments, Physiological Indices, and ChlF Parameters}

Table 4 displays the relationships among leaf pigments (Car and $\mathrm{Chl}_{\mathrm{ab}}$ ), physiological measurements (An and gs), dark-adapted ChlF parameters ( $\mathrm{Fo}, \mathrm{Fm}$, and $\mathrm{Fv} / \mathrm{Fm}$ ), and steady-state ChlF parameters (Fo', Fs, Fm', Fv'/Fm', NPQ, and Y(II), ETR) acquired during the 2014 to 2015 growing season. The results showed that $\mathrm{Fv} / \mathrm{Fm}$ and $\mathrm{Fv}^{\prime} / \mathrm{Fm}^{\prime}$ have better relationships with the majority of items listed in Table 4 than other ChlF parameters. For instance, among the dark-adapted ChlF parameters, $\mathrm{Fv} / \mathrm{Fm}$ was significantly related to $\mathrm{Car}, \mathrm{Ch}_{\mathrm{ab}}$, An, gs, $\mathrm{Fm}, \mathrm{Fm}^{\prime}, \mathrm{Fv}^{\prime} / \mathrm{Fm}^{\prime}$, and $\mathrm{Y}$ (II) with $\mathrm{R}^{2}>0.5$ and $\mathrm{p}$ value $<0.001$. Other crop traits which showed moderately significant relationships with $\mathrm{Fv} / \mathrm{Fm}$ (at $p<0.01)$ were Fs $\left(R^{2}=0.20\right)$. Fo' and ETR had a remarkable relationship with Fv/Fm at the $p<0.05$ level $\left(\mathrm{R}^{2}=0.13\right.$ and 0.15$)$. For the steady-state ChlF parameters, $\mathrm{Fv}^{\prime} / \mathrm{Fm}^{\prime}$ was significantly related with Car, Chl $a$ ab, An, gs, Fv'/Fm', Fm', Y(II), and ETR $\left(R^{2}=0.34,0.35,0.47,0.29,0.58,0.59,0.45\right.$, and 0.41 , respectively; $\mathrm{p}<0.001$ ). Fm and NPQ also had significant relationships with $\mathrm{Fv}^{\prime} / \mathrm{Fm}^{\prime}$. In general, 
$\mathrm{Fv} / \mathrm{Fm}$ and $\mathrm{Fv}^{\prime} / \mathrm{Fm}^{\prime}$ were the representative ChlF parameters in dark- and light-adapted conditions. Due to their fundamental significance and practical utility, they are the subjects of our research, and discussed in later sections.

\subsection{Dynamic Changes of Fv/Fm And Fv'/Fm' under Different $N$ Treatments during the Growing Season}

Figure 1A-D (Figure S1A-C, Figure S2A-C, Figure S3A-C, and Figure S4A-C) show the dynamic variation of $\mathrm{Fv} / \mathrm{Fm}$ for winter wheat leaves in various treatments during the 2014 to 2015 growing season. The $\mathrm{Fv} / \mathrm{Fm}$ of wheat leaves tended to increase with increasing $\mathrm{N}$ application, especially for the second and third leaves (Figure S1B,C). As shown in Figure 1A, Fv/Fm of wheat leaves in three N conditions increased from DAS 164 to DAS 172, and then decreased gradually from DAS 172 to DAS 187. The leaves in these three positions yielded a consistent tendency in the case of the Fv/Fm variation from DAS 164 to DAS 187 (Figure S1A-C, Figure S2A-C, Figure S3A-C and Figure S4A-C). However, the first expanded leaf under the N0 treatment, yielded a slightly different result (Figure S1A). The Fv/Fm kept increasing until DAS 179, and then decreased.

The temporal patterns of $\mathrm{Fv}^{\prime} / \mathrm{Fm}^{\prime}$ measured during the 2014 to 2015 growing season were exhibited in Figure 1E-H, Figure S1D-F, Figure S2D-F, Figure S3D-F and Figure S4D-F). The Fv'/Fm' values under $\mathrm{N} 4$ applications were usually larger than that in $\mathrm{N} 2$ cases, but for the first leaves, it was slightly smaller than that in N2 cases from DAS 164 to DAS 179 (Figure S1D), but slightly larger from DAS 179 to DAS 187. The $\mathrm{Fv}^{\prime} / \mathrm{Fm}^{\prime}$ values of the second and third leaves in the $\mathrm{N} 2$ and $\mathrm{N} 4$ cases were relatively close to that in the N2 treatment from DAS 164 to DAS 172 (Figure S1E,F), and higher than that in the $\mathrm{N} 2$ condition from DAS 172 to DAS 187. It was shown obviously that the Fv'/Fm' in the N2 and N4 treatments were higher than that in N0 case regardless of which leaf position. The Fv'/Fm' of the top three leaves increased gradually from DAS 164, and reached the maximum at DAS 172 or DAS 179. The $\mathrm{Fv}^{\prime} / \mathrm{Fm}^{\prime}$ of the third leaves decreased more sharply than that of the first and second leaves. 
Table 4. Relationships among leaf pigments, physiological indices, and ChlF parameters acquired during the 2015 growing season considering all data and all $\mathrm{N}$ treatments. The red color indicates significant correlations among $\mathrm{Fv} / \mathrm{Fm}, \mathrm{Fv}^{\prime} / \mathrm{Fm}^{\prime}$, and other parameters listed in this table $(\mathrm{p}<0.05)$.

\begin{tabular}{|c|c|c|c|c|c|c|c|c|c|c|c|c|c|c|}
\hline & \multicolumn{2}{|c|}{ Leaf Pigment } & \multicolumn{2}{|c|}{$\begin{array}{l}\text { Physiological } \\
\text { Indices }\end{array}$} & \multicolumn{3}{|c|}{$\begin{array}{c}\text { Dark-adapted ChlF } \\
\text { Parameters }\end{array}$} & \multicolumn{7}{|c|}{ Steady-state ChlF Parameters } \\
\hline & Car & $\mathrm{Chl}_{\mathrm{ab}}$ & An & gs & Fo & Fm & $\mathrm{Fv} / \mathrm{Fm}$ & Fo' $^{\prime}$ & Fs & $\mathrm{Fm}^{\prime}$ & $\mathrm{Fv}^{\prime} / \mathrm{Fm}^{\prime}$ & NPQ & $\mathrm{Y}(\mathrm{II})$ & ETR \\
\hline Car & 1 & & & & & & & & & & & & & \\
\hline $\mathrm{Chl}_{\mathrm{ab}}$ & $0.83^{* * *}$ & 1 & & & & & & & & & & & & \\
\hline An & $0.41^{* * *}$ & $0.32^{* * *}$ & 1 & & & & & & & & & & & \\
\hline gs & $0.32^{* * *}$ & $0.26^{* *}$ & 0.75 & 1 & & & & & & & & & & \\
\hline Fo & 0.0008 & 0.011 & 0.083 & 0.016 & 1 & & & & & & & & & \\
\hline Fm & $0.20^{* * *}$ & $0.35^{* * *}$ & $0.12^{*}$ & $0.087^{*}$ & $0.54^{* * *}$ & 1 & & & & & & & & \\
\hline $\mathrm{Fv} / \mathrm{Fm}$ & $0.51^{* * *}$ & $0.60^{* * *}$ & $0.55^{* *}$ & $0.32^{* * *}$ & 0.017 & $0.54^{* * *}$ & 1 & & & & & & & \\
\hline $\mathrm{Fo}^{\prime}$ & $0.11^{* *}$ & $0.11^{*}$ & 0.042 & 0.048 & 0.051 & $0.15^{*}$ & $0.13^{*}$ & 1 & & & & & & \\
\hline Fs & $0.13^{*}$ & $0.24^{* * *}$ & 0.0059 & 0.0097 & $0.34^{* *}$ & $0.53^{* * *}$ & $0.20^{* *}$ & $0.46^{* * *}$ & 1 & & & & & \\
\hline $\mathrm{Fm}^{\prime}$ & $0.32^{* * *}$ & $0.30^{* * *}$ & $0.30^{* *}$ & $0.22^{* *}$ & 0.0014 & $0.20^{* *}$ & $0.52^{* * *}$ & $0.54^{* * *}$ & $0.31^{* *}$ & 1 & & & & \\
\hline $\mathrm{Fv}^{\prime} / \mathrm{Fm}^{\prime}$ & $0.34^{* * *}$ & $0.35^{* * *}$ & $0.47^{* * *}$ & $0.29^{* * *}$ & 0.017 & $0.17^{* *}$ & $0.58^{* * *}$ & 0.0073 & 0.045 & $0.59^{* * *}$ & 1 & & & \\
\hline NPQ & 0.035 & 0.0043 & $0.13^{*}$ & 0.078 & $0.22^{* *}$ & $0.20^{* *}$ & 0.085 & $0.12^{*}$ & 0.014 & $0.31^{* *}$ & $0.25^{* *}$ & 1 & & \\
\hline $\mathrm{Y}(\mathrm{II})$ & 0.063 & 0.016 & $0.39^{* *}$ & $0.24^{* *}$ & 0.0009 & 0.066 & $0.33^{* * *}$ & 0.0056 & $0.18^{* *}$ & $0.25^{* *}$ & $0.45^{* * *}$ & $0.53^{* * *}$ & 1 & \\
\hline ETR & 0.063 & 0.016 & $0.40^{* *}$ & $0.24^{* *}$ & $0.37^{* * *}$ & 0.065 & $0.15^{*}$ & 0.0055 & $0.18^{* *}$ & $0.25^{* *}$ & $0.41^{* * *}$ & $0.53^{* * *}$ & $0.99^{* * *}$ & 1 \\
\hline
\end{tabular}



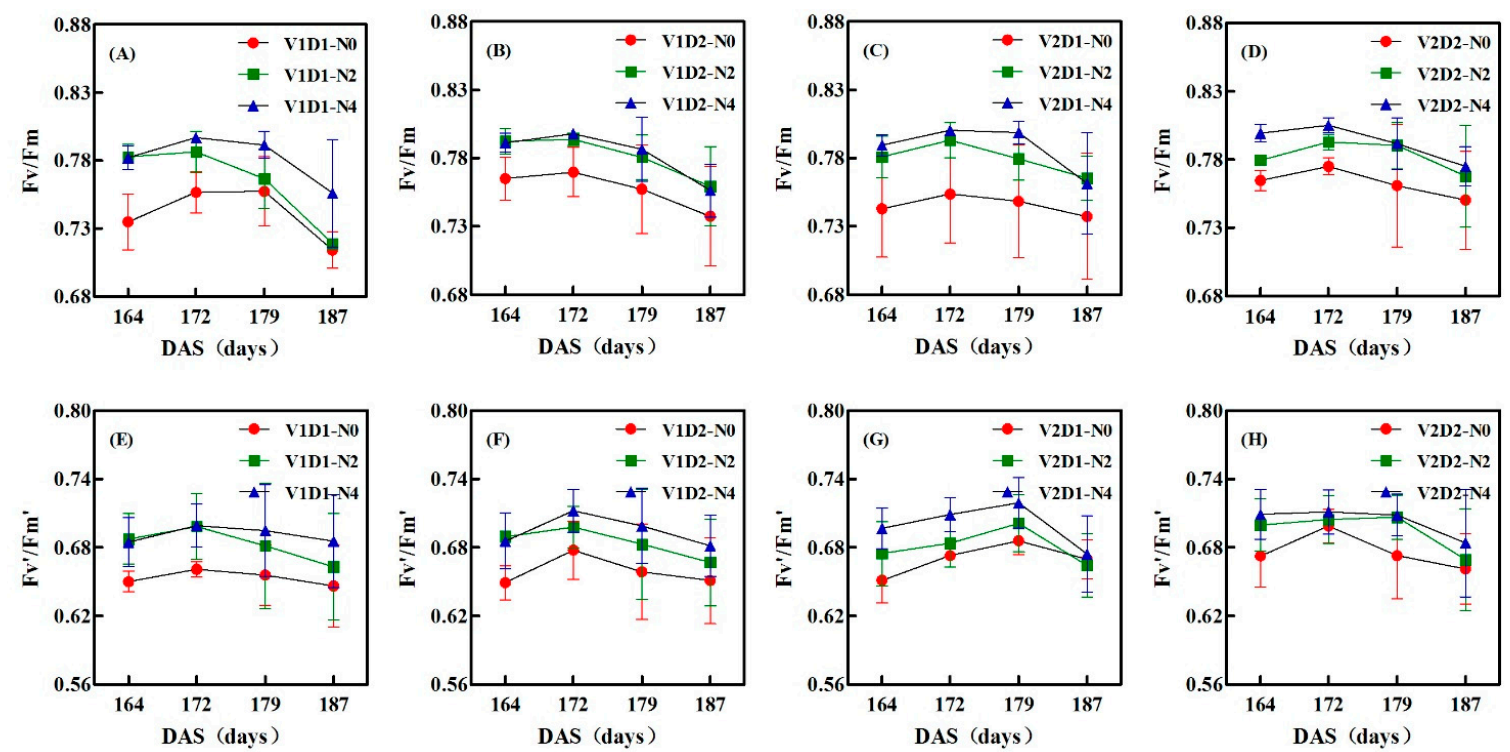

Figure 1. Variations of $\mathrm{Fv} / \mathrm{Fm}(\mathbf{A}-\mathbf{D})$ and $\mathrm{Fv}^{\prime} / \mathrm{Fm}^{\prime}(\mathbf{E}, \mathbf{F}, \mathbf{H})$ for leaves in all treatments under different $\mathrm{N}$ levels during the 2014 to 2015 growing season. V1 and V2 represent the wheat cultivar Shengxuan 6, and Yangmai 18. D1 and D2 mean the plant density of 25 and $40 \mathrm{~cm}$. N0, N2, and N4 indicate the N treatments of 0, 150, and $300 \mathrm{~kg} /$ ha, respectively. (A and E, the leaf of VID1; B and F, the leaf of V1D2;

$\mathbf{C}$ and $\mathbf{G}$, the leaf of V2D1; D and $\mathbf{H}$, the leaf of V2D2).

\subsection{Semi-empirical Models for Estimating the Leaf Fv/Fm And Fv'/Fm' Using Spectral Features}

Tables 5 and 6 show the performance of three types of spectral features (VIs, REP, and wavelet feature) for monitoring leaf $\mathrm{Fv} / \mathrm{Fm}$ and $\mathrm{Fv}^{\prime} / \mathrm{Fm}^{\prime}$ in calibration and validation datasets.

\subsubsection{Performance of VIs-based $\mathrm{Fv} / \mathrm{Fm}$ and $\mathrm{Fv}^{\prime} / \mathrm{Fm}^{\prime}$ Models in Calibration and Validation Datasets}

The best-fit functions for the relationships between the reflectance ratio VIs and wheat leaf $\mathrm{Fv} / \mathrm{Fm}$ and $\mathrm{Fv}^{\prime} / \mathrm{Fm}^{\prime}$ were mainly linear, with $\mathrm{Rc}^{2}$ values ranging from 0.22 to 0.67 for $\mathrm{Fv} / \mathrm{Fm}$, and 0.35 to 0.56 for $\mathrm{Fv}^{\prime} / \mathrm{Fm}^{\prime}$. Only the R685/R655 showed logarithmic relationships with $\mathrm{Fv} / \mathrm{Fm}$. For both Fv/Fm and $\mathrm{Fv}^{\prime} / \mathrm{Fm}^{\prime}$, the CUR exhibited the best goodness of fit among all the reflectance ratio VIs in the calibration dataset (Figure 2A,F), superior to R680/R630, followed by R685/R655 and R750/R800. When applying the reflectance ratio VIs regression models to the validation dataset, the RRMSEv produced ranged from $1.95 \%$ to $3.43 \%$ and from $4.28 \%$ to $5.51 \%$ for predictive $\mathrm{Fv} / \mathrm{Fm}$ and $\mathrm{Fv}^{\prime} / \mathrm{Fm}^{\prime}$, separately. The CUR yielded the best performance in validation for predicting $\mathrm{Fv} / \mathrm{Fm}\left(\mathrm{Rv}^{2}=0.50\right.$, Bias $=0.0056$, RMSEv $=0.012$, and RRMSEv $=1.95 \%)$ shown in Figure $3 \mathrm{~A}$ and for $\mathrm{Fv}^{\prime} / \mathrm{Fm}^{\prime}\left(\mathrm{Rv}^{2}=0.38\right.$, Bias $=0.0072$, RMSEv $=0.030$, and RRMSEv $=4.28 \%$ ) exhibited in Figure 3F.

For the derivative VIs listed in Table 3, the best fitness between Fv/Fm and D705/D722, $\mathrm{D} \lambda \rho / \mathrm{D}(\lambda \rho+12 \mathrm{~nm})$, and DPi were linear, except for D730/D706 and $\mathrm{D} \lambda \rho / \mathrm{D} 720$ which were logarithmic. The $\mathrm{Rc}^{2}$ values of the derivative VIs and leaf Fv/Fm ranged from 0.38 to 0.64. D705/D722, D730/D706, and $\mathrm{D} \lambda \rho / \mathrm{D} 720$ gave similar performances in the calibration dataset $\left(\mathrm{R}_{C}{ }^{2}=0.63\right)$ (Table 5). When detecting $\mathrm{Fv}^{\prime} / \mathrm{Fm}^{\prime}$ using derivative VIs, all the best fitting lines were linear, with $\mathrm{Rc}^{2}$ values from 0.22 to 0.60 . D730/D706 and D $\lambda \rho / D 720$ performed similar, which were inferior to D705/D722. When the regression models of the calibration dataset were applied to the datasets acquired during the 2015 to 2016 growing season, the RRMSEv ranged from $1.87 \%$ to $3.69 \%$ for estimating $\mathrm{Fv} / \mathrm{Fm}$, and $3.96 \%$ to $6.41 \%$ for $\mathrm{Fv}^{\prime} / \mathrm{Fm}^{\prime}$. The D705/D722 produced the best prediction accuracy for $\mathrm{Fv} / \mathrm{Fm}\left(\mathrm{R}_{\mathrm{V}}{ }^{2}=0.50\right.$, Bias $=0.0037, \operatorname{RMSEv}=0.015$, and RRMSEv $=1.87 \%)$ shown in Table 5 and for $\mathrm{Fv}^{\prime} / \mathrm{Fm}^{\prime}\left(\mathrm{RV}^{2}=0.40\right.$, Bias $=0.0031$, RMSEv $=0.028$, and RRMSEv $=3.96 \%$ ) depicted in Table 6 , significantly better than that of the other derivative VIs. 
Table 5. Performance of models for estimating the Fv/Fm based on vegetation indices (VIs), red edge positions (REPs), and wavelet features in calibration and validation.

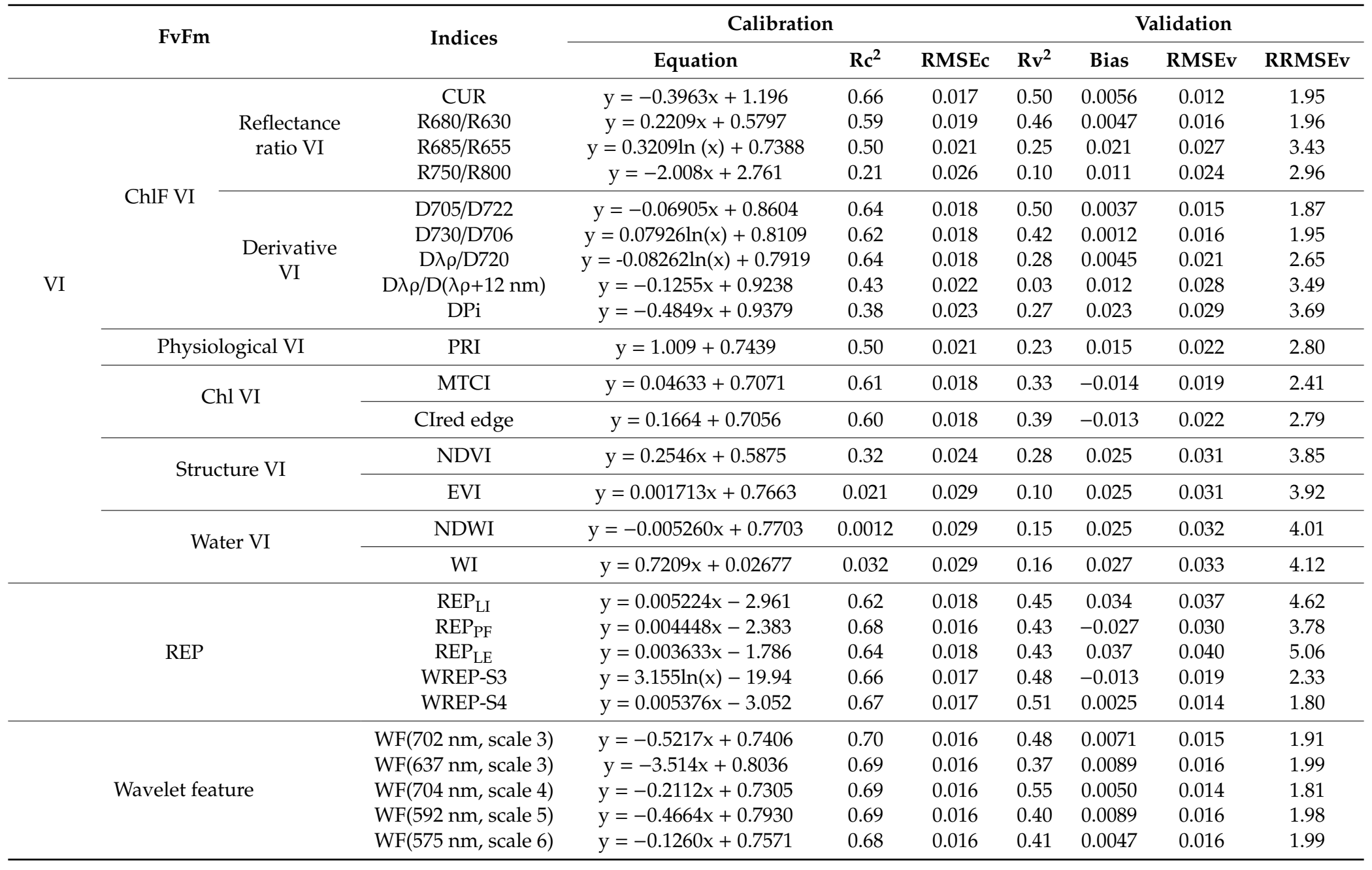


Table 6. Performance of models for estimating the $\mathrm{Fv}^{\prime} / \mathrm{Fm}^{\prime}$ based on VIs, REPs, and wavelet features in calibration and validation.

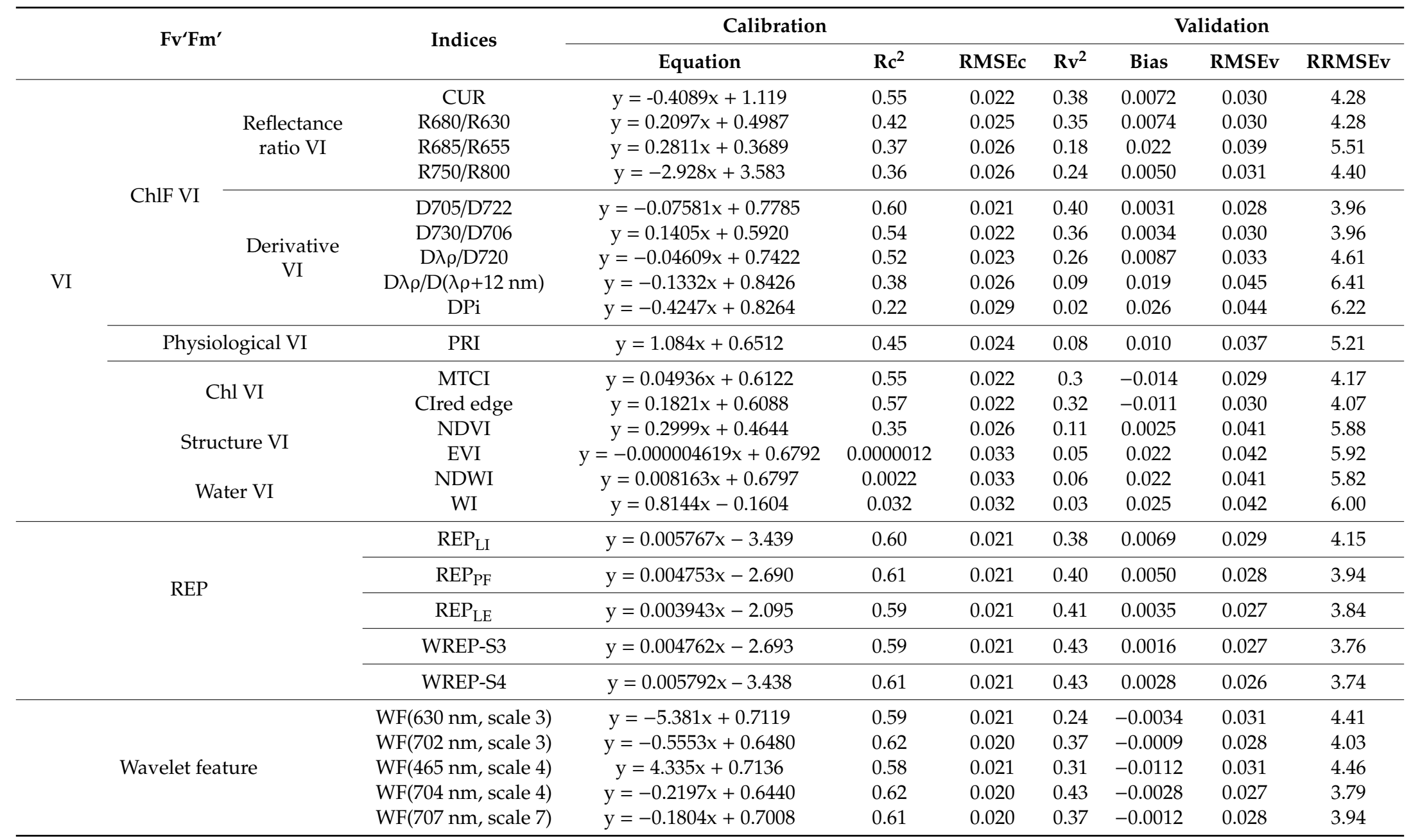



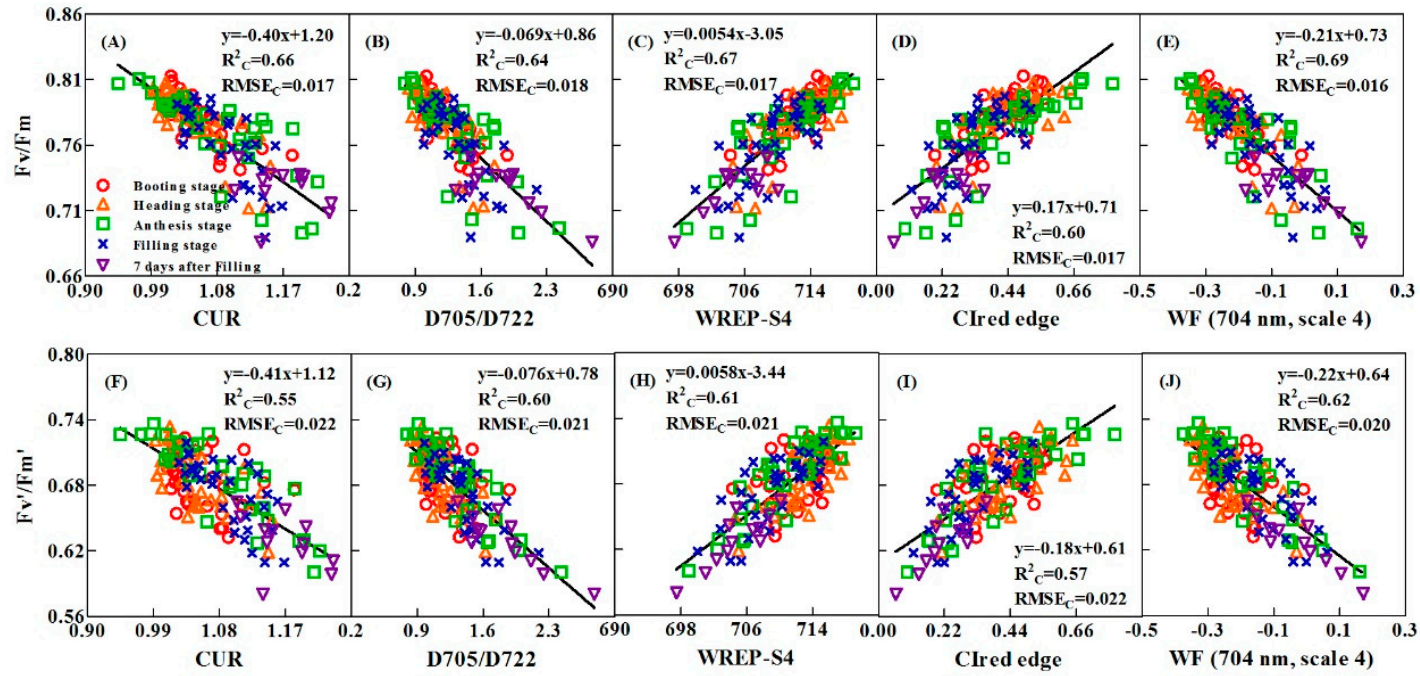

Figure 2. Leaf $\mathrm{Fv} / \mathrm{Fm}$ and $\mathrm{Fv}^{\prime} / \mathrm{Fm}^{\prime}$ values plotted against five spectral features which performed best in each group: Curvature index (CUR) (A,F), D705/D722 (B,G), wavelet-based REP (WREP-S4) (C,H), CIred edge (D,I), and wavelet feature (WF) $(704 \mathrm{~nm}$, scale 4$)(\mathbf{E}, \mathbf{J})$. The black solid line is for all data in the growing season. All regressions are statistically significant $(\mathrm{p}<0.01)$. Data points from the booting, heading, anthesis, and filling stages are shown in red (cycle), magenta (triangle), green (square), and blue (cross), respectively.
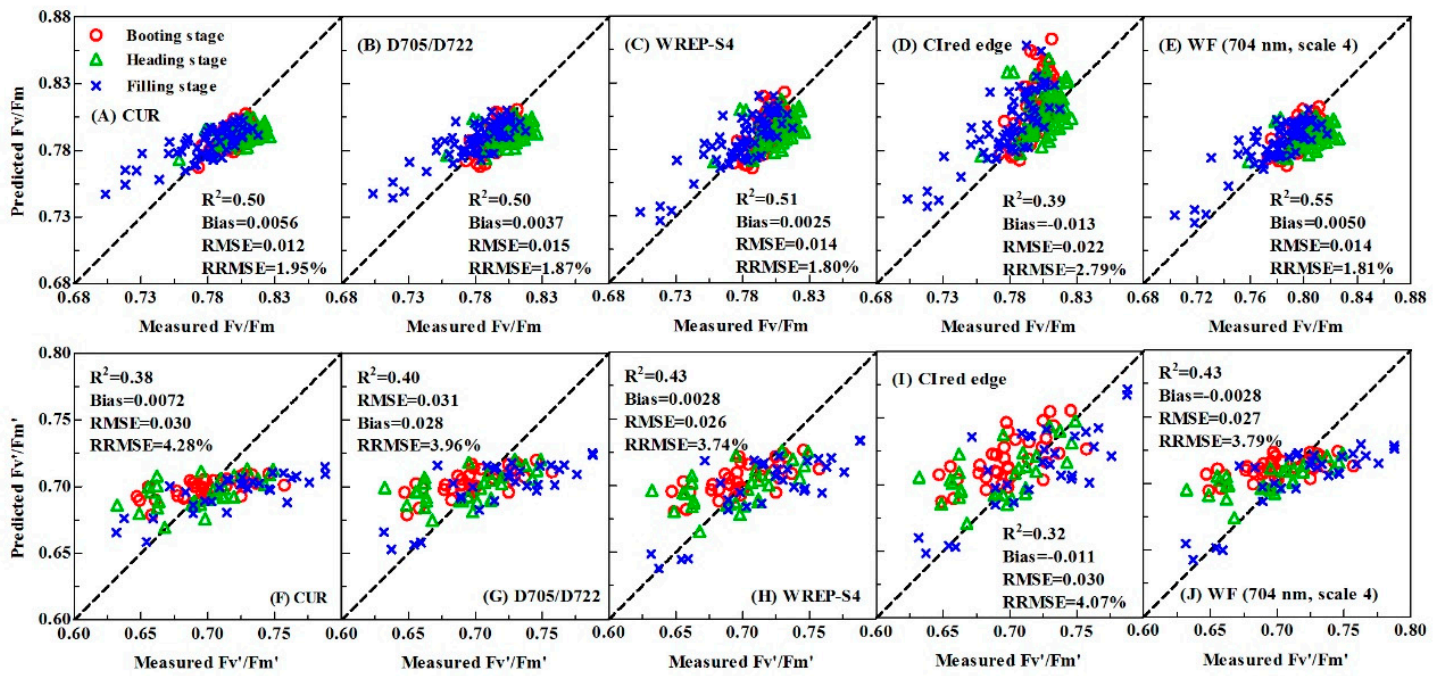

Figure 3. Plots of measured and predicted leaf $\mathrm{Fv} / \mathrm{Fm}$ and $\mathrm{Fv}^{\prime} / \mathrm{Fm}^{\prime}$ developed from the regression models using CUR (A,F), D705/D722 (B,G), WREP-S4 (C,H), CIred edge (D,I), and wavelet feature (WF) (704 nm, scale 4) (E,J). Data points from the booting, heading, and filling stages are shown in red (cycle), green (triangle), and blue (cross), respectively.

The PRI, as a physiological VI, showed a little worse calibration performance than some ChlF VIs, and it did not yield a positive result in validation. The sensitivities of structure VIs and water VIs to Fv/Fm and Fv'/Fm' were much poorer than that of Chl VIs. The MTCI and CIred edge had similar performances for predicting $\mathrm{Fv} / \mathrm{Fm}$ and $\mathrm{Fv}^{\prime} / \mathrm{Fm}^{\prime}$ in the calibration dataset, with $\mathrm{Rc}^{2}$ around 0.61 and 0.55 , respectively. But with regards to the predictive accuracy of leaf Fv/Fm inversion, the best validation results were obtained by CIred edge $\left(\mathrm{R}_{\mathrm{V}}^{2}=0.39\right.$, Bias $=-0.013, \mathrm{RMSEv}=0.022$, and RRMSEv $=2.79 \%$, which also was the most accurate Chl VIs to derive leaf Fv' $/ \mathrm{Fm}^{\prime}\left(\mathrm{R}_{\mathrm{V}}{ }^{2}=0.32\right.$, Bias $=-0.011, \mathrm{RMSEv}=0.030$, and RRMSEv $=4.07 \%$ ). In addition, the VIs related to structure properties and water content were proven to be invalid to estimate $\mathrm{Fv} / \mathrm{Fm}$ and $\mathrm{Fv}^{\prime} / \mathrm{Fm}^{\prime}$ in the validation dataset. 


\subsubsection{Performance of REP for Predicting Leaf $\mathrm{Fv} / \mathrm{Fm}$ and $\mathrm{Fv}^{\prime} / \mathrm{Fm}^{\prime}$ in Calibration and Validation}

The best relationships between the REPs and Fv/Fm all were linear except WREP-S3, and all linear functions for $\mathrm{Fv}^{\prime} / \mathrm{Fm}^{\prime}$. There are not much difference between the five REPs monitoring A Fv/Fm or $\mathrm{Fv}^{\prime} / \mathrm{Fm}^{\prime}$. However, with regards to the validation performance, WREP-S4 showed better performance in estimating leaf $\mathrm{Fv} / \mathrm{Fm}$ and $\mathrm{Fv}^{\prime} / \mathrm{Fm}^{\prime}$ than the other four REPs, with the highest predictive accuracy $\left(\mathrm{R}_{\mathrm{V}}{ }^{2}=0.51\right.$ for $\mathrm{Fv} / \mathrm{Fm}$ and $\mathrm{R}_{\mathrm{V}}{ }^{2}=0.43$ for $\left.\mathrm{Fv}^{\prime} / \mathrm{Fm}^{\prime}\right)$ and the lowest error (RRMSEv $=1.80 \%$ for $\mathrm{Fv}^{\prime} / \mathrm{Fm}^{\prime}$ and RRMSEv $=3.74 \%$ for $\mathrm{Fv}^{\prime} / \mathrm{Fm}^{\prime}$ ) as shown in Figure $2 \mathrm{C}, \mathrm{H}$, followed by WREP-S3.

\subsubsection{Models for Estimating the Leaf $\mathrm{Fv} / \mathrm{Fm}$ and $\mathrm{Fv}^{\prime} / \mathrm{Fm}^{\prime}$ Based on Wavelet Features}

Figure $4 \mathrm{~A}$ shows the top $1 \%$ wavelet feature regions relevant to the ChlF parameter $\mathrm{Fv} / \mathrm{Fm}$ for the dataset acquired during the 2014 to 2015 growing season. These wavelet features were formed in five feature regions in the visible and near-infrared regions. All of them occurred from scale 3 to scale 6. These five wavelet features were identified as significantly related to $\mathrm{Fv} / \mathrm{Fm}(\mathrm{P}<0.0001)$ with $\mathrm{Rc}^{2}$ values for the linear regressions ranging from 0.68 to 0.70 (Table 5). According to the $\mathrm{Rc}^{2}$ values, the wavelet features sensitive to Fv/Fm were WF (702 nm, scale 3), WF (637 nm, scale 3), WF (704 nm, scale 4), WF (592 nm, scale 5), and WF (575 nm, scale 6) in sequence, which gave similar performances for the estimation of the $\mathrm{Fv} / \mathrm{Fm}$ of winter wheat. When the regression models of the calibration dataset were used as the validation dataset, WF (704 nm, scale 4) showed the best transferability yielding the highest precision $\left(\mathrm{Rv}^{2}=0.55\right)$ and lowest predicted error $(\mathrm{Bias}=0.0050$, $\mathrm{RMSEv}=0.014$, and RRMSEv $=1.81 \%$; Figure $3 \mathrm{E}$ and Table 5).

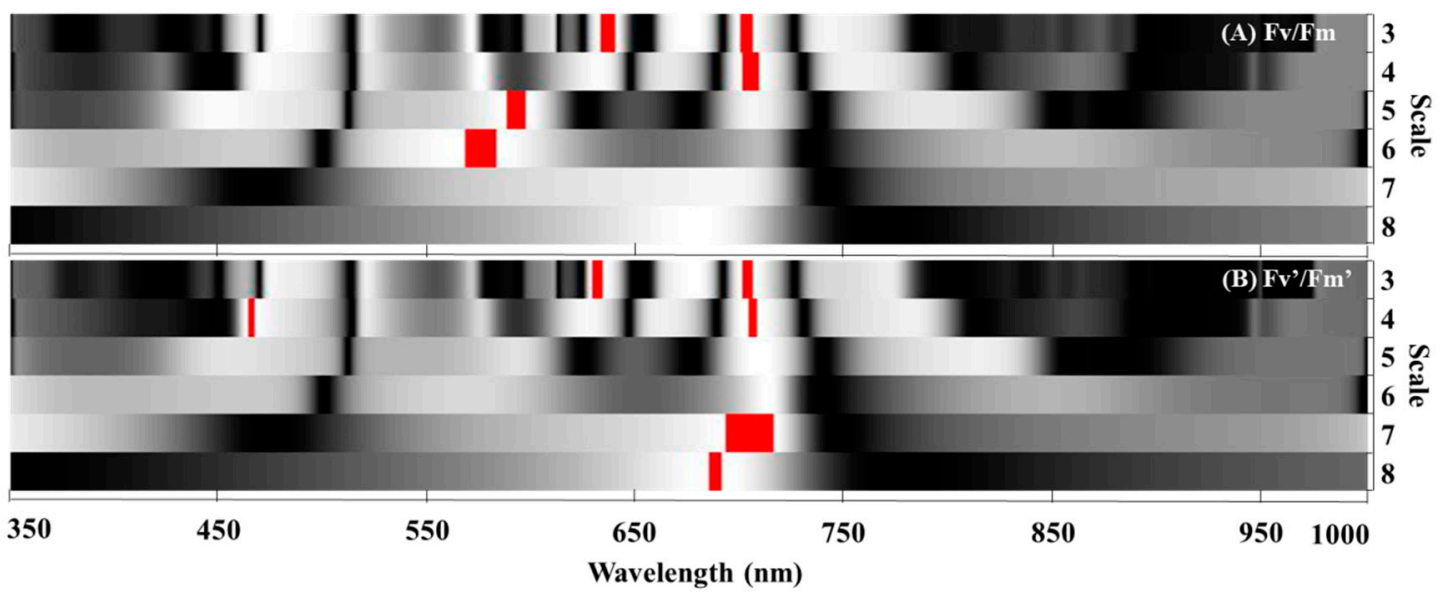

Figure 4. The wavelet feature regions with the top $1 \%$ coefficients of determination between wavelet power and wheat leaf $\mathrm{Fv} / \mathrm{Fm}$ and $\mathrm{Fv}^{\prime} / \mathrm{Fm}^{\prime}$ for the dataset acquired during the 2014 to 2015 growing season.

Six feature regions relevant to variation of leaf $\mathrm{ChlF}$ parameter $\mathrm{Fv}^{\prime} / \mathrm{Fm}^{\prime}$ were determined according to their relationships with extracted wavelet power, which covered the visible region between 460 and $710 \mathrm{~nm}$ (Figure 4B), distributing on scale 3, 4, 7, and 8. These feature regions are WF (465 nm, scale 4), WF (630 nm, scale 3), WF (702 nm, scale 3), WF (704 nm, scale 4), WF (707 nm, scale 7), and WF (688 nm, scale 8). The wavelength of the first feature was closed to the blue band, in which the $\mathrm{N}$-carbon compounds have absorption characteristics. Other features were located in the red region and red edge area, including the $630 \mathrm{~nm}, 688 \mathrm{~nm}$, and 702 to $707 \mathrm{~nm}$, in which the reflectance is strongly absorbed by Chl. Among these six wavelet features, the top five features were selected to estimate the leaf $\mathrm{Fv}^{\prime} / \mathrm{Fm}^{\prime}$. All of the best-fit functions for the relationships between wavelet features and leaf $\mathrm{Fv}^{\prime} / \mathrm{Fm}^{\prime}$ were linear, with $\mathrm{Rc}^{2}$ values from 0.58 to 0.62 . The WF ( $465 \mathrm{~nm}$, scale 4 ) located in the blue region produced the worst agreement in the calibration dataset and the independent validation dataset as compared with the other four wavelet features. And regardless of which dataset, the best predictive 
accuracy and the lowest predictive error were found when using the WF (704 nm, scale 4), followed by WF (702 nm, scale 3), and WF (707 nm, scale 7).

\section{Discussion}

\subsection{Signature Components of Leaf Chlf Parameters and Their Variation with N Regimes}

Compared with other ChlF parameters in dark-adapted and steady-state condition, Fv/Fm and $\mathrm{Fv}^{\prime} / \mathrm{Fm}^{\prime}$, two ChlF parameters related to the photochemical efficiency of PSII, were more significantly correlated with leaf pigments, physiological indices, and other ChlF parameters (Table 4). Fv/Fm and $\mathrm{Fv}^{\prime} / \mathrm{Fm}^{\prime}$, relevant to the quantum function of the PSII reaction center, have been used to study plant response to environmental factors [43-45], analyze the correlation to net photosynthesis and quantum yield, indicate leaf $\mathrm{N}$ and sulfur content, $\mathrm{Chl}$ concentration [46], and detect plant stress and evaluate the nutritional and healthy status of plants [47]. Therefore, $\mathrm{Fv} / \mathrm{Fm}$ and $\mathrm{Fv}^{\prime} / \mathrm{Fm}^{\prime}$ are seen as the subjects of this study due to their fundamental significance and practical utility.

Compared with the variation of L1, L2, and L3 under N0, N2, and N4 treatments (Figure S1) for wheat leaf in V1D1, those in V1D2, V2D1, and V2D2 were similar overall. This seasonal trend is common, existing in multiple genotypes of wheat sown with different plant densities. In general, the changes of $\mathrm{Fv} / \mathrm{Fm}$ and $\mathrm{Fv}^{\prime} / \mathrm{Fm}^{\prime}$ for wheat leaves at different leaf positions and different $\mathrm{N}$ treatments were basically the same as the findings of other studies [4]. At the heading or anthesis stages, Fv/Fm and $\mathrm{Fv}^{\prime} / \mathrm{Fm}^{\prime}$ reached a peak, and then decreased, which is mainly due to the exuberant growth and strong physiological activity of plants. Within a certain range of fertilizer applications (i.e., N0 to N2), $\mathrm{Fv} / \mathrm{Fm}$ increased with an increase of $\mathrm{N}$ application [4]. It shows that the efficiency of light energy conversion and potential activity of photosynthetic reaction center were increased, with decreased damage on the photosynthetic apparatus. However, there was a slight decrease in $\mathrm{Fv}^{\prime} / \mathrm{Fm}^{\prime}$ in the N4 treatment as compared with the N2 application (Figure 1D), and similar Fv/Fm in the N4 and N2 cases (Figure 1A) [48]. Photosynthetic capacity was not improved under excess N, which indicates that excessive $\mathrm{N}$ is not effective in photosynthetic performance. The reason why $\mathrm{N}$ can cause a change of ChlF parameters is because different $\mathrm{N}$ applications affect the photochemistry of PSII by altering the quantum yield of PSII electron transport [49].

\subsection{Comparing VIs and REPs for Quantitatively Retrieving Fv/Fm and Fv'/Fm'}

Many ChlF VIs have been proposed to exploit the effect of ChlF on the apparent reflectance spectrum in the red edge region (from 650 to $800 \mathrm{~nm}$ ) [13]. By dividing the sample into different growth periods, it was concluded that phenological stages did not cause a significant impact on the performance of these spectral features for monitoring $\mathrm{Fv} / \mathrm{Fm}$ and $\mathrm{Fv}^{\prime} / \mathrm{Fm}^{\prime}$ (S5). Among the reflectance ratio VIs, the CUR yielded the best relationship with leaf Fv/Fm and Fv'/Fm' (Figure 3A), followed by R680/R630, which was also found in the case of tracking Fv/Fm variations under various Chl contents [12]. Both R680/R630 and CUR can well capture the reflectance changes centered around $680 \mathrm{~nm}$, therefore, they can track the curvature of reflectance caused by ChlF emission (in the red edge region from $670 \mathrm{~nm}$ to $770 \mathrm{~nm}$, with the central emission at $690 \mathrm{~nm}$ and $730 \mathrm{~nm}$ ) as reported earlier [14]. Derivative VIs minimizing other confounding effects, can detect subtle changes due to the ChlF emission in the red edge region. Among all the derivative VIs listed in this study, the best predictive accuracy was found when using D705/D722 to estimate $\mathrm{Fv} / \mathrm{Fm}$ and $\mathrm{Fv}^{\prime} / \mathrm{Fm}^{\prime}$ in various N treatments, which is consistent with an independent study [13]. Our study provided confirmatory evidence that the inference of ChlF using reflectance ratio VIs and derivative VIs is feasible with acceptable accuracy.

The REP, the wavelength of the inflexion point in the red edge region of reflectance, has received much attention over the years for understanding the properties of plants, such as the Chl content, $\mathrm{N}$ content of the leaf, and the leaf area index [50,51]. Among five methods widely used to extract REP, WREP-S4 yielded more stable results than VIs relevant to ChlF, physiological status, Chl content, 
water content, and structure properties. In comparison with VIs related to physiological status, those for Chl content, water content, and structure properties were not effective for monitoring ChlF parameters. With respect to NDVI and PRI, they varied with the development of vegetation, but NDVI can be saturated before PRI [52]. And the bands sensitive to the photosynthesis and water content are definitely different. Although CIred edge showed acceptable performance in calibration, the transferability of CIred edge-based model was not ideal. However, REP can characterize signals in the red edge region, where ChlF exists. Therefore, according to the good agreement between REP and $\mathrm{Fv} / \mathrm{Fm}, \mathrm{Fv}^{\prime} / \mathrm{Fm}^{\prime}$, it implies that REP can be used as the functions of ChlF emission bands in the red edge region, which is consistent with previous theoretical descriptions of ChlF effects on reflectance or the derivative spectra [14].

\subsection{Comparison between CWA and Other Spectral Features for Estimating Fv/Fm and Fv'/Fm'}

CWA, as an effective mathematical method, has been extensively used to retrieve useful information from hyperspectral data, such as leaf biochemical parameters [25]. Comparing the wavelet features associated with Fv/Fm and Fv'/Fm', we found that WF (702 nm, scale 3), WF (637 nm, scale 3), and WF (704 nm, scale 4) were their common wavelet features. Among these three wavelet features, WF (704 nm, scale 4) outperformed and exhibited the best stability, not only for Fv/Fm estimation but also for $\mathrm{Fv}^{\prime} / \mathrm{Fm}^{\prime}$. Therefore, WF (704 nm, scale 4) is considered to be a robust spectral feature for tracking $\mathrm{Fv} / \mathrm{Fm}$ and $\mathrm{Fv}^{\prime} / \mathrm{Fm}^{\prime}$ collected throughout various significant growth stages and different $\mathrm{N}$ treatment regimes.

According to a comprehensive evaluation of the performances in calibration and validation, the reflectance ratio VI CUR, the derivative VI D705/D722, the REP extracted by WREP-S4 technique, CIred edge related to Chl content, and WF (704 nm, scale 4) derived by CWA performed best and exhibited good reliability in their respective groups. The best wavelet feature WF (704 nm, scale 4) was superior to WREP-S4, but not significantly. Both of them were extracted at the fourth scale and centered around $704 \mathrm{~nm}$. WF (704 nm, scale 4) has been used to retrieve the leaf Chl contents of cereal crops [19], and therefore it confirms that this wavelet feature is not only sensitive to Chl content but also ChlF signal. In summary, WREP-S4 and wavelet feature WF (704 nm, scale 4) permitted operational quantification of $\mathrm{Fv} / \mathrm{Fm}$ and $\mathrm{Fv}^{\prime} / \mathrm{Fm}^{\prime}$ using hyperspectral data.

On the basis of a comparison of the performance of these spectral features for detecting Fv/Fm and $\mathrm{Fv}^{\prime} / \mathrm{Fm}^{\prime}$, we concluded that Fv/Fm could be estimated more accurately than $\mathrm{Fv}^{\prime} / \mathrm{Fm}^{\prime}$. This may be because the change of Fv/Fm is very small under non-stress conditions and it is not affected by species and growth conditions. The performance of WREP and wavelet feature for detecting ChlF parameters should be tested for more vegetation types. Moreover, at the leaf scale, ChlF signal is to a certain extent influenced by environmental factors, however, when these findings are extended to the canopy and regional scales, additional complexity should be considered, such as canopy structure, canopy heterogeneity, and the interaction of ChlF signal with atmosphere.

\section{Conclusions}

In this study, three reflectance-based approaches (VIs, REPs, and wavelet features) were used to extract the optimal spectra features from apparent reflectance for estimation of two significant ChlF parameters, Fv/Fm and Fv'/Fm'. They were related to photosynthetic apparatus, especially PSII activity, and were more relevant to pigment content and physiological parameters than other ChlF parameters. In each group, the spectral feature most relevant to $\mathrm{Fv} / \mathrm{Fm}$ and $\mathrm{Fv}^{\prime} / \mathrm{Fm}^{\prime}$ were the same, and all of them were calculated based on bands in the red edge region, where the ChlF signal occurs. The results also showed that the ChlF VIs (CUR and D705/D722) are effective indicators for the estimation of Fv/Fm and $\mathrm{Fv}^{\prime} / \mathrm{Fm}^{\prime}$ under various treatment regimes. Meanwhile, the performance of REPs and wavelet feature for the estimation of $\mathrm{Fv} / \mathrm{Fm}$ and $\mathrm{Fv}^{\prime} / \mathrm{Fm}^{\prime}$ were evaluated and compared with that of traditional VIs related to ChlF, physiological status, Chl content, water content, and structure properties. The accuracy of WREP-S4 in both calibration and validation was better than REPs extracted by other 
algorithms. Among all wavelet features, WF (704 nm, scale 4) yielded the best predictive accuracy for Fv/Fm and Fv'/Fm' estimation. Additionally, both WREP-S4 and WF (704 nm, scale 4) were all centered around $704 \mathrm{~nm}$. This work demonstrates that the use of WREP-S4 and WF (704 nm, scale 4) provide more reliable assessments of the ChlF parameters $\mathrm{Fv} / \mathrm{Fm}$ and $\mathrm{Fv}^{\prime} / \mathrm{Fm}^{\prime}$ than empirical methods based on traditional VIs. Therefore, the red edge region can be exploited for estimation of Fv/Fm and $\mathrm{Fv}^{\prime} / \mathrm{Fm}^{\prime}$. These findings provide new insight for quantifying ChlF signal more accurately using reflectance-based approaches.

Supplementary Materials: The following are available online at http://www.mdpi.com/2072-4292/11/23/2838/s1, Figure S1: The variations of Fv/Fm (A, B, C) and Fv'/Fm' (D, E, F) for leaves in V1D1 treatments under different $\mathrm{N}$ levels in the 2014-2015 growing season. V1 represents the wheat cultivar Shengxuan 6, D1 means the rowledge $25 \mathrm{~cm}$. (A, D: the top first expanded leaf (L1); B, E: the top second expanded leaf (L2); C, F: the top third expanded leaf (L3)). N0, N2 and N4 indicate the N treatments of 0, 150 and $300 \mathrm{~kg} / \mathrm{ha}$, respectively., Figure S2. The variations of Fv/Fm (A, B, C) and Fv'/Fm' (D, E, F) for leaves in V1D2 treatments under different N levels in the 2014-2015 growing season. V1 represents the wheat cultivar Shengxuan 6, D2 means the rowledge $40 \mathrm{~cm}$. (A, D: the top first expanded leaf (L1); B, E: the top second expanded leaf (L2); C, F: the top third expanded leaf (L3)). N0, N2 and $\mathrm{N} 4$ indicate the $\mathrm{N}$ treatments of 0,150 and $300 \mathrm{~kg} / \mathrm{ha}$, respectively. Figure S3. The variations of Fv/Fm (A, B, C) and $\mathrm{Fv}^{\prime} / \mathrm{Fm}^{\prime}$ (D, E, F) for leaves in V2D1 treatments under different N levels in the 2014-2015 growing season. V2 represents the wheat cultivar Yangmai 18, D1 means the rowledge $25 \mathrm{~cm}$. (A, D: the top first expanded leaf (L1); B, E: the top second expanded leaf (L2); C, F: the top third expanded leaf (L3)). N0, N2 and N4 indicate the N treatments of 0,150 and $300 \mathrm{~kg} / \mathrm{ha}$, respectively. Figure S4. The variations of Fv/Fm $(\mathrm{A}, \mathrm{B}, \mathrm{C})$ and Fv'/Fm' (D, E, F) for leaves in V2D2 treatments under different $\mathrm{N}$ levels in the 2014-2015 growing season. V2 represents the wheat cultivar Yangmai 18, D2 means the rowledge $40 \mathrm{~cm}$. (A, D: the top first expanded leaf (L1); B, E: the top second expanded leaf (L2); C, F: the top third expanded leaf (L3)). N0, N2 and N4 indicate the N treatments of 0, 150 and $300 \mathrm{~kg} / \mathrm{ha}$, respectively.

Author Contributions: M.J. and X.Y. designed the experiment; M.J., D.L., Y.W., and X.W. contributed to the field experiments and data collection; M.J. D.L., R.C., T.C., Y.Z., and X.Y. performed the overall data analysis; T.C., Y.Z., X.Y., C.X., G.O., H.L., and C.Z. contributed to data collection; M.J., D.L., R.C., and X.Y. drafted the manuscript; all authors read and approved the final manuscript.

Funding: This work was supported by the National Natural Science Foundation of China $(31671582,31971780)$; Key projects (advanced technology) of Jiangsu province (BE 2019383), Jiangsu; the National Key Research and Development Program of China (2016YFD0300601); the Qinglan Project; the Qinghai Project of Transformation of Scientific and Technological Achievements (2018-NK-126); the Xinjiang Corps Great Science and Technology Projects (2018AA00403); the 111 project (B16026), and the Jiangsu Collaborative Innovation Center for Modern Crop Production, China.

Acknowledgments: We would like to thank Xiao Zhang, Xue Ma, Chen Zhou, and Yong Liu for their help in the data collection. The authors also thank the anonymous reviewers for their detailed suggestions for improving the manuscript.

Conflicts of Interest: The authors declare no conflict of interest.

\section{References}

1. Krause, G.H.; Weis, E. Chlorophyll fluorescence as a tool in plant physiology: II. Interpretation of fluorescence signals. Photosynth. Res. 1984, 5, 139-157. [CrossRef] [PubMed]

2. Schreiber, U. Chlorophyll fluorescence as a tool in plant physiology I. The measuring systems. Photosynth. Res. 1983, 4, 361-373. [CrossRef] [PubMed]

3. Portable Fluorometer PAM-2000 and Data Acquisition Software DA-2000; Heinz-Walz-GmbH: Effeltrich, Germany, 1993.

4. Liu, R.X.; Wang, Y.H.; Chen, B.L.; Guo, W.Q.; Zhou, Z.G. Effects of nitrogen levels on photosynthesis and chlorophyll fluorescence characteristics under drought stress in cotton flowering and boll-forming stage. Acta Agron. Sin. 2008, 34, 675-683. [CrossRef]

5. Baker, N.R. Chlorophyll fluorescence: A probe of photosynthesis In Vivo. Annu. Rev. Plant Biol. 2008, 59, 89-113. [CrossRef] [PubMed]

6. Butler, W.L.; Kitajima, M. Fluorescence quenching in photosystem II of chloroplasts. Biochim. Biophys. Acta Bioenerg. 1975, 376, 116-125. [CrossRef]

7. Feng, W.; He, L.; Zhang, H.Y.; Guo, B.B.; Zhu, Y.J.; Wang, C.Y.; Guo, T.C. Assessment of plant nitrogen status using chlorophyll fluorescence parameters of the upper leaves in winter wheat. Eur. J. Agron. 2015, 64, 78-87. [CrossRef] 
8. Faraloni, C.; Cutino, I.; Petruccelli, R.; Leva, A.R.; Lazzeri, S.; Torzillo, G. Chlorophyll fluorescence technique as a rapid tool for in vitro screening of olive cultivars (Olea europaea L.) tolerant to drought stress. Environ. Exp. Bot. 2011, 73, 49-56. [CrossRef]

9. Bengtsson, G.B.; Schöner, R.; Lombardo, E.; Schöner, J.; Borge, G.I.A.; Bilger, W. Chlorophyll fluorescence for non-destructive measurement of flavonoids in broccoli. Postharvest Biol. Technol. 2006, 39, 291-298. [CrossRef]

10. Netto, A.T.; Campostrini, E.; de Oliveira, J.G.; Bressan-Smith, R.E. Photosynthetic pigments, nitrogen, chlorophyll a fluorescence and SPAD-502 readings in coffee leaves. Sci. Hortic. 2005, 104, 199-209. [CrossRef]

11. Ač, A.; Malenovsky, Z.; Olejnícková, J.; Galle, A.; Rascher, U.; Mohammed, G. Meta-analysis assessing potential of steady-state chlorophyll fluorescence for remote sensing detection of plant water, temperature and nitrogen stress. Remote Sens. Environ. 2015, 168, 420-436. [CrossRef]

12. Zarco-Tejada, P.J.; Miller, J.R.; Mohammed, G.H.; Noland, T.L. Chlorophyll fluorescence effects on vegetation apparent reflectance: I. Leaf-level measurements and model simulation. Remote Sens Environ. 2000, 74, 582-595. [CrossRef]

13. Zarco-Tejada, P.J.; Miller, J.R.; Mohammed, G.H.; Noland, T.L.; Sampson, P.H. Chlorophyll Fluorescence Effects on Vegetation Apparent Reflectance: II. Laboratory and Airborne Canopy-Level Measurements with Hyperspectral Data. Remote Sens Environ. 2000, 74, 596-608. [CrossRef]

14. Zarco-Tejada, P.J.; Pushnik, J.C.; Dobrowski, S.; Ustin, S.L. Steady-state chlorophyll a fluorescence detection from canopy derivative reflectance and double-peak red-edge effects. Remote Sens Environ. 2003, 84, $283-294$. [CrossRef]

15. Dobrowski, S.Z.; Pushnik, J.C.; Zarco-Tejada, P.J.; Ustin, S.L. Simple reflectance indices track heat and water stress-induced changes in steady-state chlorophyll fluorescence at the canopy scale. Remote Sens Environ. 2005, 97, 403-414. [CrossRef]

16. Pérez-Priego, O.; Zarco-Tejada, P.J.; Miller, J.R.; Sepulcre-Canto, G.; Fereres, E. Detection of water stress in orchard trees with a high-resolution spectrometer through chlorophyll fluorescence in-filling of the O2-A band. IEEE Trans. Geosci. Remote Sens. 2005, 43, 2860-2869. [CrossRef]

17. Zarco-Tejada, P.J.; Miller, J.R.; Mohammed, G.H.; Noland, T.L.; Sampson, P.H. Estimation of chlorophyll fluorescence under natural illumination from hyperspectral data. Int. J. Appl. Earth Obs. Geoinf. 2001, 3, 321-327. [CrossRef]

18. Gamon, J.A.; Serrano, L.; Surfus, J.S. The photochemical reflectance index: An optical indicator of photosynthetic radiation-use efficiency across species, functional types, and nutrient levels. Oecologia 1997, 112, 492-501. [CrossRef]

19. Li, D.; Cheng, T.; Zhou, K.; Zheng, H.B.; Yao, X.; Tian, Y.C.; Zhu, Y.; Cao, W.X. WREP: A wavelet-based technique for extracting the red edge position from reflectance spectra for estimating leaf and canopy chlorophyll contents of cereal crops. ISPRS J. Photogram. Remote Sens. 2017, 129, 103-117. [CrossRef]

20. Guyot, G.; Baret, F. Utilisation de la haute resolution spectrale pour suivre l'etat des couverts vegetaux. Spect. Signat. Objects Remote Sens. 1988, 287, 279.

21. Cho, M.A.; Skidmore, A.K. A new technique for extracting the red edge position from hyperspectral data: The linear extrapolation method. Remote Sens. Environ. 2006, 101, 181-193. [CrossRef]

22. Dawson, T.P.; Curran, P.J. Technical note: A new technique for interpolating the reflectance red edge position. Int. J. Remote Sens. 1998, 19, 2133-2139. [CrossRef]

23. Cheng, T.; Rivard, B.; Sánchez-Azofeifa, A.G.; Féret, J.B.; Jacquemoud, S.; Ustin, S.L. Predicting leaf gravimetric water content from foliar reflectance across a range of plant species using continuous wavelet analysis. J. Plant Physiol. 2012, 169, 1134-1142. [CrossRef] [PubMed]

24. Torrence, C.; Compo, G.P. A practical guide to wavelet analysis. Bull. Am. Meteorol. Soc. 1998, 79, 61-78. [CrossRef]

25. Cheng, T.; Rivard, B.; Sanchez-Azofeifa, A.G.; Feret, J.B.; Jacquemoud, S.; Ustin, S.L. Deriving leaf mass per area (LMA) from foliar reflectance across a variety of plant species using continuous wavelet analysis. ISPRS J. Photogram. Remote Sens. 2014, 87, 28-38. [CrossRef]

26. Meroni, M.; Rossini, M.; Guanter, L.; Alonso, L.; Rascher, U.; Colombo, R.; Moreno, J. Remote sensing of solar-induced chlorophyll fluorescence: Review of methods and applications. Remote Sens. Environ. 2009, 113, 2037-2051. [CrossRef] 
27. Lichtenthaler, H.K.; Wellburn, A.R. Determinations of total carotenoids and chlorophyll a and b of leaf extracts in different solvents. Biochem. Soc. Trans. 1983, 603, 591-592. [CrossRef]

28. Calatayud, Á.; Bautista, A.S.; Pascual, B.; Maroto, J.V.; López-Galarza, S. Use of chlorophyll fluorescence imaging as diagnostic technique to predict compatibility in melon graft. Sci Hortic. 2013, 149, 13-18. [CrossRef]

29. Sharma, D.K.; Fernández, J.O.; Rosenqvist, E.; Ottosen, C.O.; Andersen, S.B. Genotypic response of detached leaves versus intact plants for chlorophyll fluorescence parameters under high temperature stress in wheat. J. Plant Physiol. 2014, 171, 576-586. [CrossRef]

30. Cheng, T.; Riaño, D.; Ustin, S.L. Detecting diurnal and seasonal variation in canopy water content of nut tree orchards from airborne imaging spectroscopy data using continuous wavelet analysis. Remote Sens. Environ. 2014, 143, 39-53. [CrossRef]

31. Li, D.; Wang, X.; Zheng, H.; Zhou, K.; Yao, X.; Tian, Y.; Zhu, Y.; Cao, W.; Cheng, T. Estimation of area- and mass-based leaf nitrogen contents of wheat and rice crops from water-removed spectra using continuous wavelet analysis. Plant Methods 2018, 14, 76. [CrossRef]

32. Bruce, L.M.; Li, J. Wavelets for computationally efficient hyperspectral derivative analysis. IEEE Trans. Geosci. Remote Sens. 2001, 39, 1540-1546. [CrossRef]

33. Peñuelas, J.; Baret, F.; Filella, I. Semi-Empirical Indices to Assess Carotenoids/Chlorophyll-a Ratio from Leaf Spectral Reflectance. Photosynthetica 1995, 31, 221-230.

34. Dash, J.; Curran, P.J. The MERIS terrestrial chlorophyll index. Int. J. Remote Sens. 2004, 25, 5403-5413. [CrossRef]

35. Gitelson, A.A.; Gritz, Y.; Merzlyak, M.N. Relationships between leaf chlorophyll content and spectral reflectance and algorithms for non-destructive chlorophyll assessment in higher plant leaves. J. Plant Physiol. 2003, 160, 271-282. [CrossRef]

36. Gitelson, A.A.; Viña, A.; Ciganda, V.; Rundquist, D.C.; Arkebauer, T.J. Remote estimation of canopy chlorophyll content in crops. Geophys. Res. Lett. 2005, 32. [CrossRef]

37. Rouse, J.W. Monitoring the Vernal Advancement and Retrogradation (Greenwave Effect) of Natural Vegetation. In NASA/GSFCT Technical Report; NTRS: Chicago, IL, USA, 1974.

38. Jiang, Z.; Huete, A.; Didan, K.; Miura, T. Development of a two-band enhanced vegetation index without a blue band. Remote Sens. Environ. 2008, 112, 3833-3845. [CrossRef]

39. Gao, B.C. NDWI-A normalized difference water index for remote sensing of vegetation liquid water from space. Remote Sens. Environ. 1996, 58, 257-266. [CrossRef]

40. Peñuelas, J.; Filella, I.; Biel, C.; Serrano, L.; Save, R. The reflectance at the $950-970 \mathrm{~nm}$ region as an indicator of plant water status. Int. J. Remote Sens. 1993, 14, 1887-1905. [CrossRef]

41. Guyot, G.; Baret, F.; Jacquemoud, S. Imaging spectroscopy for vegetation studies. Imag. Spectrosc. Fundam. Prospect. Appl. 1992, 2, 145-165.

42. Baker, N.R.; Rosenqvist, E. Applications of chlorophyll fluorescence can improve crop production strategies: An examination of future possibilities. J. Exp. Bot. 2004, 55, 1607-1621. [CrossRef]

43. Zhang, R.; Sharkey, T.D. Photosynthetic electron transport and proton flux under moderate heat stress. Photosynth. Res. 2009, 100, 29-43. [CrossRef] [PubMed]

44. Kalaji, H.M.; Jajoo, A.; Oukarroum, A.; Brestic, M.; Zivcak, M.; Samborska, I.A.; Cetner, M.D.; Lukasik, I.; Goltsev, V.; Ladle, R.J. Chlorophyll a fluorescence as a tool to monitor physiological status of plants under abiotic stress conditions. Acta Physiol. Plant. 2016, 38, 102. [CrossRef]

45. Rastogi, A.; Zivcak, M.; Tripathi, D.K.; Yadav, S.; Kalaji, H.M. Phytotoxic effect of silver nanoparticles in Triticum aestivum: Improper regulation of photosystem I activity as the reason for oxidative damage in the chloroplast. Photosynthetica 2019, 57, 209-216. [CrossRef]

46. Zhou, Y.; Huang, L.F.; Du, Y.S.; Yu, J.Q. Greenhouse and field cucumber genotypes use different mechanisms to protect against dark chilling. Funct. Plant Biol. 2004, 31, 1215-1223. [CrossRef]

47. Singh, S.K.; Reddy, V.R.; Fleisher, D.H.; Timer, D.J. Relationship between photosynthetic pigments and chlorophyll fluorescence in soybean under varying phosphorus nutrition at ambient and elevated CO2. Photosynthetica 2017, 55, 421-433. [CrossRef]

48. Lin, Y.C.; Yue-Gao, H.U.; Ren, C.Z.; Guo, L.C.; Wang, C.L.; Jiang, Y.; Wang, X.J.; Hlatshwayo, P.; Zeng, Z.H. Effects of Nitrogen Application on Chlorophyll Fluorescence Parameters and Leaf Gas Exchange in Naked Oat. J. Integr. Agric. 2013, 12, 2164-2171. [CrossRef] 
49. Baret, F.; Jacquemoud, S.; Guyot, G.; Leprieur, C. Modeled analysis of the biophysical nature of spectral shifts and comparison with information content of broad bands. Remote Sens. Environ. 1992, 41, 133-142. [CrossRef]

50. Broge, N.H.; Leblanc, E. Comparing prediction power and stability of broadband and hyperspectral vegetation indices for estimation of green leaf area index and canopy chlorophyll density. Remote Sens. Environ. 2000, 76, 156-172. [CrossRef]

51. Mutanga, O.; Skidmore, A.K. Red edge shift and biochemical content in grass canopies. ISPRS J. Photogram. Remote Sens. 2007, 62, 34-42. [CrossRef]

52. Daumard, F.; Goulas, Y.; Champagne, S.; Fournier, A.; Ounis, A.; Olioso, A.; Moya, I. Continuous Monitoring of Canopy Level Sun-Induced Chlorophyll Fluorescence During the Growth of a Sorghum Field. IEEE Trans. Geosci. Remote 2012, 50, 4292-4300. [CrossRef]

(C) 2019 by the authors. Licensee MDPI, Basel, Switzerland. This article is an open access article distributed under the terms and conditions of the Creative Commons Attribution (CC BY) license (http://creativecommons.org/licenses/by/4.0/). 